\title{
ПОНЯТИЕ КОММУНИКАЦИИ В ТЕОРИИ ОБЩЕСТВА НИКЛАСА ЛУМАНА
}

\begin{abstract}
С.В. Лебедева
В рамках современной парадигмы коммуникации оформились, по признанию многих авторов, две противоположные концепции, представленные в немецкой коммуникативной философии и социологии Ю. Хабермасом и его последователями и Н. Луманом. Как уже отмечалось в наших предыдущих работах $[1,2]$, позиция Ю. Хабермаса базируется на европейской традиции, которая учитывает роль и значимость субъекта в социальных процессах. Хабермасовская теория коммуникативного действия широко известна и достаточно исследована. В то же время о концепции Н. Лумана, вызывающей сейчас повышенный интерес, так сказать нельзя. Как считает А. Назарчук, «и сегодня мировая философская общественность едва ли может похвастаться, что сумела воспринять и подхватить его идеи» [7, с. 156]. Связано это и со сложностью языка, и с нестандартностью мышления Н. Лумана, и с оригинальностью подхода к созданию общей теории общества, которая стала, в известном роде, поворотом в социальной философии и социологии.

В чем суть такого поворота, и какую роль в лумановской концепции общества играет понятие коммуникации, мы попытаемся рассмотреть в данной статье.

Свою системную теорию общества Луман противопоставляет традиционной, существенно зависимой, по его мнению, от различения между субъектом и объектом. Отказываясь от такого различения, Луман кладет в основу создаваемой им теории общества дифференцию между системой и окружающим миром, или, как он пишет, придерживается дифференциалистского подхода, подхода теории различия (диф-
\end{abstract}

Актуальні проблеми духовності:

зб. наук. праць / Ред.: Я.В. Шрамко

Вип. 10. - Кривий Ріг, 2009, 146-155 
ференции) [3, с.68]. Общество как открытая система, по утверждению Лумана, основывается на отношениях между системой и средой. Эти отношения не статичны, а динамичны, они являются каналами осуществления каузальности. Исходя из такой позиции, он приходит к выводу, что ни одна система не может существовать без окружающего мира, иначе она достигла бы состояния энтропии или вообще не реализовалась, потому что в момент возникновения она тотчас же распалась бы, достигнув состояния лишенного различий равновесия [3, c. 68].

Различение системы и окружающего мира создается самой системой. Именно посредством собственных операций система проводит границу, отличает себя от окружающего мира и только потому и только так ее можно наблюдать как систему [3, с. 94]. При этом система не может использовать свои собственные операции для установления связи с окружающим миром. Это связано с тем, что операции от начала до конца, то есть в значении событий, всегда возможны только в системе. Они не могут быть использованы для проникновения в окружающий мир. Такое утверждение Лумана основано на том, что, когда граница между системой и окружением пересечена, системные операции таковыми уже не являются, а должны стать чем-то другим. Поэтому возможности подсоединения, продолжения, следующие операции система должна искать только внутри себя. Следовательно, система целиком и полностью основана на собственных операциях [3, с.96].

Это возможно благодаря способности системы выстраивать собственную структурную комплексность. Окружающий мир отличается большей комплексностью, чем система. Здесь речь идет о «разности» комплексности [3, с. 174]. В этой связи возникает вопрос, как системе удается справляться с более комплексным окружающим миром, если ни одна система не обладает необходимой мощностью, чтобы приспосабливать свое состояние к происходящему в окружении. Взаимодействуя с окружающим миром, система должна фокусировать или игнорировать, демонстрировать безразличие или создавать специальные механизмы для управления комплексностью. Это возможно в ходе редукции комплексности - с одной стороны, в отношении окружающего мира, а с другой, в отношении себя самой.

Следует отметить, что в литературе редко встречается определение понятий комплексности и редукции комплексности. Эти термины, видимо, не до конца проработаны в понятийном отношении и самим Луманом. Он рассматривает понятие комплексности через понятие различения, считая, что проблема комплексности-это проблема порога, 
начиная с которого каждый элемент системы не может быть связан со всеми другими элементами. Поэтому отношения между элементами могут устанавливаться только очень выборочно. В этом случае существует сеть исключений и включений возможных операций в систему, а алгоритмы отбора становятся все более требовательными, то есть селективными, контингентными или информативными. Они требуют, чтобы выполнялось то-то и то-то, а не что-либо другое. Таким образом, система является комплексной, так как представляет собой смешение избыточности и вариативности, в ней заключено «единство некоторого множества элементов», рассматриваемых как операции [6, с. 147]. Выбор необходимых системе операций основан на способности системы редуцировать комплексность окружения. В ходе такой редукции происходит исключительно избирательное подсоединение элементов системы. А на основе собственной комплексности системы осуществляется их упорядоченность и происходит выделение системы из окружающего мира.

Чтобы эффективно взаимодействовать со своей внешней средой, которая является более сложной и комплексной по сравнению с системой, общество вынуждено вырабатывать новые подсистемы и устанавливать между ними различные соотношения. В результате теория общества Лумана, по его утверждению, является теорией всеохватывающей социальной системы, которая включает в себя все другие социальные системы, выступающие ее функциональными частями [6, c.83]. При этом система, где образуются функциональные подсистемы, воспроизводится посредством дальнейшего различения между частной системой и окружающим миром. С точки зрения частной системы остальная часть охватывающей системы теперь представляет собой окружающий мир. Такая системная дифференция порождает внутрисистемные окружающие миры, а каждая частная система воспроизводит охватывающую систему, к которой она принадлежит, посредством собственного различения системы и окружающего мира [4, c.10]. Таким образом, в системной теории Лумана следует выделить отношения типа система/окружающий мир и отношения типа система/система. Благодаря различению системы и внешнего мира система постигает единство охватывающей системы. Посредством отношений система/система она постигает только фрагменты мира или общества. Здесь возникает вопрос о том, как происходит взаимодействие системы и окружающего мира и систем между собой. Теория общества Лумана в целом зависит от ответа на этот вопрос, который является достаточно трудным. Для ответа на него Луман использует понятие «стру- 
ктурные сопряжения» [6, с. 106].

Структурные сопряжения ограничивают область возможных структур, с помощью которых система может проводить свой аутопойезис. Понятие аутопойезиса является ключевым в теории Лумана. Заимствуя его у Умберто Матураны, Луман понимает под ним самовоспроизводство. Это означает, что в системе существует определенный тип операций, к которым подсоединяются операции такого же типа. Подсоединение осуществляется выборочно, в результате чего происходит создание системы. Следовательно, аутопойетические системы Луман определяет как системы, способные в сети своих элементов порождать эти элементы и собственные структуры. Элементы системы (если их рассматривать во времени, то речь идет об операциях), из которых состоят аутопойетические системы, не существуют независимо. Они связаны друг с другом, вступают в единое целое и порождаются системой благодаря тому, что признаются как различия, как информации. Поэтому они являются единицами применения для производства следующих единиц применения, для которых в окружающем мире системы не существует никакого соответствия [6, с.68]. Следовательно, аутопойезис - это производство системы посредством самой системы.

Таким образом, всякая аутопойетическая система оперирует как структурно детерминированная система, то есть она может детерминировать собственные операции посредством собственных структур. Структурное сопряжение исключает, что реалии окружающего мира могут соразмерно собственным структурам специфицировать то, что происходит в системе. Оно не определяет происходящее в системе, но должно предпосылаться, ибо в противном случае аутопойезис прекратился бы, а система перестала бы существовать. Структурные сопряжения предполагают также, что система внутри себя производит избыток возможностей. Так она способна ограничивать свои свободы, осуществляя это таким способом, который может варьироваться от одной ситуации к другой. Для психических и для социальных систем эти излишки возможностей задаются медиумом $c$ мыслл. Для разрешения этих неопределенностей, которое в каждом случае должно происходить внутри нее, система нуждается в отправных точках, которые она обнаруживает в собственной памяти, но также может заимствовать и у структурных сопряжений.

Следует отметить, что аутопойетические системы тоже сопряжены между собой. При этом структурные сопряжения выказывают высокую степень стабильности, так как они совместимы с любым аутопойетически возможным структурным развитием систем. Именно че- 
рез структурные сопряжения система может включаться в высококомплексные условия окружающего мира, не испытывая при этом необходимости перерабатывать или реконструировать их комплексность. Охватывая лишь ограниченный сектор окружающего мира, структурные сопряжения исключают все то, что способно воздействовать на систему деструктивно. Так обеспечивается автономия аутопойезиса системы и выстраивание собственной комплексности.

Таким образом, система у Лумана является операционно закрытой и самодостаточной. Она может конституировать собственные операции, подсоединяя их к другим собственным операциям. Этим объясняется способность системы к само- и ино-референциям, так как ино-референция - это соотнесение операций друг с другом и их способность к внутреннему подсоединению, а само-референция - это воспроизводство системой самой себя. При этом актуализация само-референции сопровождается ино-референцией и наоборот. Само-референция подразумевает также и то, что система, будучи оперативно замкнутой, постоянно воспроизводит в себе различение системы и окружающего мира. Такое различение, как считает Луман, делает возможными процессы, способствующие дальнейшему развитию системы в ходе процессирования следующих операций.

Исходя из выше изложенного, можно кратко охарактеризовать системную теорию Лумана в целом. Дифференция система / окружающий мир, лежащая в ее основе, делает возможным определение общества как системы, которая является аутопойетической, то есть самодостаточной и способной к самовоспроизводству собственных элементов, операционно замкнутой, самореферентной и структурно комплексной. Общество как система состоит из многочисленных функциональных систем, которые сопряжены друг с другом и с окружением и которым присущи все выше обозначенные черты. Существование таких систем сводится к редукции комплексности окружения, а также к построению своей собственной комплексности, оперируя медиумом смысла.

Следовательно, система общества Лумана характеризуется не определенной «сущностью». Ее характеризует та операция, в ходе которой производится и воспроизводится общество. И эта операция - коммуникация [6, с. 72$]$.

Самовоспроизводство системы через коммуникацию четко отграничивает систему от ее внешнего мира. Это значит, что в обществе происходит воспроизводство коммуникаций из коммуникаций. В отличие от традиционной концепции общества и коммуникации (представленных, например, Ю. Хабермасом и его последователями), Луман утвер- 
ждает, что никакой конкретный человек не является необходимым для общества. Его утверждение основано на различении общества и окружающего мира, исходя из которого, по мнению Лумана, человека как сознательное существо - следует отнести либо к системе, либо к окружающему миру (разделить его на части эмпирически невозможно). Если человека рассматривать как часть системы общества, то теорию дифференциации, считает автор, нужно было бы формулировать, исходя из распределения людей на слои, нации, группы и т.д. Это противоречит концепции прав человека и пониманию равенства. Поэтому человека в его целостности, с его душой и телом, Луман рассматривает как часть окружающего мира, системы общества. «Не человек способен коммуницировать - коммуницировать способна лишь коммуникация» $[6$, с. 110$]$.

Однако это не означает, что коммуникация возможна вне сознания. Подобно коммуникационным системам, Луман рассматривает сознания тоже как системы. При этом сознания являются операционно замкнутыми и неспособны поддерживать контакт друг с другом, то есть «не существует никакой коммуникации сознания с сознанием, и не существует никакой коммуникации между индивидом и обществом» [6, с.110]. Объясняет это Луман тем, что в структурном сопряжении «сознание-коммуникация» задействованы аутопойетические системы-системы сознаний и системы коммуникаций. Они изначально настроены друг на друга и функционируют незаметно и скоординировано. Такие отношения Луман называет взаимопроникновением, сравнивая их с отношениями нервных клеток и мозга. Автор выделяет два механизма структурных сопряжений коммуникации и сознания. Одним из этих механизмов является язык. Он функционирует, не подвергаясь психической рефлексии и социальному комментированию. Но это не исключает как размышлений над выбором слов, если сознание усматривает для этого повод, так и обговаривания способов выражений, если всплывает проблема понимания для социальной системы. Таким образом, язык ортогонален к аутопойетическим процессам в использующих его системах [6, с. 114]. Луман утверждает также, что языку не присущ никакой собственный тип оперирования. Он должен осуществляться или как мышление, или как коммуникация. Следовательно, язык не является настоящей системой. Он зависит от того, что системы сознания и система коммуникации общества продолжают свой аутопойезис в виде закрытых операций. Если бы этого не происходило, считает автор, то всякая речь сразу же прекратилась бы, а вскоре после этого исчезла бы и возможность мыслить в форме языка 
[6, c. 116].

Вторым механизмом структурного сопряжения систем сознания и систем коммуникаций Луман считает схемы («фреймы», «скрипты», «когнитивные карты» или «имплицитные теории») [6, с. 115]. Эти понятия обозначают смысловые комбинации, служащие в обществе и психических системах для образования памяти. При использовании таких схем коммуникация предполагает, что всякое задействованное сознание понимает, что подразумевается. В то же время коммуникация предполагает и неустановленность того, как системы сознания обращаются со схемой и какие подсоединяющиеся коммуникации являются результатом использования схем. Схемы могут конкретизироваться и приспосабливаться к любой потребности. Как редукции структурной потребности, схемы служат для выстраивания операционной комплексности системы и тем самым для текущего приспособления структурного сопряжения психических и социальных систем к меняющимся типам ситуаций. Здесь Луман снова акцентирует внимание на том, что функции и механизмы структурного сопряжения не должны осуществляться в операциях системы, а могут предпосылаться им как незаметно и беспрерывно функционирующие.

Благодаря названным механизмам из структурного сопряжения систем сознания и систем коммуникаций и возникает текущая коммуникация, которая служит базовой операцией для образования социальных систем. Как элементарная операция общества коммуникация представляет собой событие, привязанное к моменту времени, которое, как только это событие состоялось, тотчас снова исчезает. Это характерно и для всех компонентов коммуникации: для информации, способной лишь однажды удивить, для сообщения, которое как действие привязано к какому-то мгновению, и для понимания, которое неповторимо, но доступно в воспоминании.

Характеристика коммуникации как единства, состоящего из трех компонент - информации, сообщения и понимания, производимых коммуникацией, исключает возможность приписывания одной из компонент онтологической первичности. Также, по мнению Лумана, единство коммуникативных событий не является ни объективным, ни субъективным, ни социально дедуцируемым. Поэтому коммуникация создает в себе медиум смысл, в котором она устанавливает связь между информацией, сообщением и пониманием. Компоненты коммуникации, благодаря смыслу, взаимно предполагают друг друга. Следовательно, онтологически они не фиксируют свои проявления как свойства мира, а должны их искать в переходе от одной коммуникации к 
соответствующей другой.

Чтобы понять, как происходит такой переход, следует, как нам представляется, охарактеризовать каждый компонент коммуникации. Информация для Лумана не является чем-то стабильным, допускающим транспортировку, как это принято считать традиционно. Луман рассматривает информацию как неожиданный отбор из многих возможностей $[6$, с. 74], которая изменяет состояние перерабатывающей ее системы. Информация должна, по его мнению, порождаться внутрисистемно, так как предполагает сравнение с ожиданиями. Так же информацию невозможно получить пассивно из сигналов, воспринимаемых из окружающего мира. Связано это с тем утверждением Лумана, что информация всегда содержит произвольную компоненту предвосхищения своего дальнейшего протекания. Следовательно, еще до начала порождения информации к ней должен сформироваться интерес. Именно интерес будет определять возникновение информации, которая, являясь дифференцией, изменяющей состояние системы, производит следующую дифференцию - информации и сообщения. Это различение коммуникация порождает благодаря своему протеканию и посредством него наблюдает за тем, что операция имеет место.

Сообщение Луман понимает как действие, которое обусловливает протекание коммуникации во времени. Оно имеет в коммуникации минимальную функциональную нагрузку, выбирая должна ли информация быть распространена и каким образом возможно ее распространение.

Следующая дифференция, между информацией и сообщением, это понимание. Понимание - ключевой момент коммуникации, который, по мнению Лумана, должна создавать она сама. Это осуществляется благодаря неслучайному характеру осетевления коммуникативных событий, то есть благодаря само-референциальной структуре процесса коммуникации. Автор указывает также на то, что в процессе понимания соучаствуют и процессы сознания, однако никто из участников коммуникации не может знать, как оно задействовано в конкретном случае, - причем, ни по отношению к другим участвующим, ни по отношению к самому себе. Связано это, по мнению Лумана, с тем, что коммуникация не в состоянии контролировать то, что совершается одновременно с нею, то есть то, что происходит в момент понимания [6, c. 75]. Следовательно, порождая понимание (или непонимание), всякая коммуникационная единица замыкается и приобретает форму перехода к другой коммуникации, которая может заняться прояснениями или 
обратиться к другим темам.

Таким образом, в ходе операционного процесса коммуникация (посредством того, что она осуществляется) воспроизводит замкнутость системы. В зависимости от того, как она осуществляется, коммуникация воспроизводит дифференцию закрытости и открытости. Так возникает система, которая на основе своей закрытости открыта в своих операциях для окружающего мира.

В целом, исследование системной теории Н. Лумана позволяет нам сделать следующие выводы.

Общество - это целостная система, состоящая из множества социальных систем, выступающих ее функциональными частями. В качестве своей базовой операции общество порождает коммуникацию, которая является связующим звеном для всех его функциональных подсистем. Коммуникация в таком обществе-это синтез трех селекций: информации, сообщения, понимания. Посредством синтеза происходит выборочное подсоединение последующих коммуникаций, которые система производит и воспроизводит в каждом своем проявлении. Поэтому, как считает Луман, коммуницировать способна лишь коммуникация, а не человек и его сознание. Человек в теории Лумана теряет функцию носителя коммуникации, то есть субъекта. Он, своего рода, комплекс, который автор относит к окружающему миру системы. Все предметы коммуникации (ее внешние миры: люди, сознания, объекты) могут быть представлены лишь коммуникативно, то есть внутри системы общества. В таком случае общество как система представляет собой замкнутую последовательность соотносящихся лишь друг с другом операций, способных к аутопойезису. Этим объясняется отказ Лумана от различения субъекта и объекта, на котором основано традиционное описание общества. В его теории определяющую роль играет дифференция система-окружающий мир. Жестко изолируя себя от окружения, система неспособна функционировать без него. Взаимодействие системы и окружающего мира происходит в ходе структурных сопряжений систем сознания и систем коммуникаций с помощью двух механизмов - языка и схем. Системы сознания в таком взаимодействии контролируют вхождение окружающего мира в системы коммуникаций, способные к сомоорганизации и самоконтролю. Здесь речь идет о том, что системы коммуникаций через системы сознания могут актуализировать необходимый для них материал окружающего мира. Следовательно, система порождает дифференцию с окружающим миром через последовательность взаимно согласующихся операций, в ходе которых возникает или продолжае- 
тся коммуникация. Таким образом, общество у Лумана не существует без коммуникации, а коммуникация невозможна вне общества. «Все, что ни происходило бы в обществе, это все - коммуникация» [3, с.92].

\section{1 Литература}

[1] Лебедева С.В. Общение. Деятельность. Коммуникация // Актуальні проблеми духовності. - Вип. 8. - Кривий Ріг, 2007. - С. 350359.

[2] Лебедева C.B. Понятие коммуникации в немецкой коммуникативной философии // Актуальні проблеми духовності. - Вип. 9. Кривий Ріг, 2008. - С. 152-161.

[3] Луман Н. Введение в системную теорию. - М.: Логос, 2007.

[4] Луман Н. Дифференция. - М.: Логос, 2006.

[5] Луман Н. Медиа коммуникации. - М.: Логос, 2005.

[6] Луман Н. Общество как социальная система. - М.: Логос, 2004.

[7] Назарчук А.В. Общество как коммуникация в трудах Никласа Лумана // Вопросы философии. - 2006. - №6. - С. 156-173. 